\title{
CHARGE TRANSFER RATE IN LIQUID-SOLID AND GAS-LIQUID-SOLID FLUIDIZED BED ELECTRODES
}

\author{
Katsuki KUSAKABE, Shigeharu MOROOKA \\ AND YASUO KATO \\ Department of Applied Chemistry, Kyushu University, \\ Fukuoka 812
}

\begin{abstract}
Copper deposition from acidic aqueous solutions containing copper ion was studied in rectangular fluidized bed electrodes for liquid-solid and gas-liquid-solid systems. The effective specific resistance of particle phase, $\rho_{m}$, was determined by comparison of the experimental potential profile with the theoretical one.

The value of $\rho_{m}$ decreased with increase in gas velocity, and the gas flow increased the total cell current by $10-30 \%$ at a given cell voltage in the range of 15 to $30 \%$ bed expansion. No explicit effects of fluidized bed height and particle diameter on $\boldsymbol{\rho}_{n n}$ were observed.

The overall effective specific resistance of bed, $\rho_{b}$, was measured with an alternating current bridge circuit, and the relationship between $\rho_{m}$ and $\rho_{b}$ is discussed. The charge transfer in the particle phase was analysed by the parallel effective resistance model based on the charge conductive mechanism and the collision mechanism.
\end{abstract}

\section{Introduction}

Recently a liquid-solid fiuidized bed electrode has attracted much attention in the field of metal winning $^{1,10,12,14,18)}$. This electrode consists of electrically conductive particles fluidized by the flow of electrolyte, and has a high electrode area per unit cell volume and good heat and mass transfer characteristics. However, a complication is the variation of electrode potential in the bed due to its three-dimensional configuration. The effective specific resistance of particle phase, $\rho_{m}$, is an important parameter in the design of the fluidized bed electrode ${ }^{4,8}$. Morooka et al. ${ }^{14)}$ reported the effects of particle diameter and electrolyte concentration on $\rho_{m}$.

The introduction of gas flow into the fluidized bed gives the following advantages to the electrode.

1) The gas flow maintains a supply of reactant for electrochemical process involving a gaseous reactant.

2) The gas flow enhances mass transfer and increase the turbulence in the bed.

Oloman et $a l^{15}{ }^{15}$ used the gas-liquid-solid fluidized bed electrode to produce hydrogen peroxide by the electroreduction of oxygen, but fundamental studies of the gas-liquid-solid fluidized bed electrode are apparently insufficient to date.

In the present paper, the potential profiles in liquidsolid and gas-liquid-solid fluidized bed electrodes are measured by means of the reduction of copper, and the effective specific resistance of particle phase is ob-

Received September 16, 1980. Correspondence concerning this article should be addressed to $\mathrm{X}$. Kato. tained. The effects of cell configuration and gas velocity on $\rho_{m}$ are studied. Furthermore, the overall effective specific resistance of the bed, $\rho_{b}$, is measured with an alternating current bridge circuit. The relationship between $\rho_{m}$ and $\rho_{b}$ is discussed with the mechanisms of charge transfer in the particle phase.

\section{Experimental Apparatus and Procedure}

\section{1 Fluidized bed electrodes}

The fluidized beds were rectangular in cross-section, as shown in Fig. 1, and were made of transparent polyvinyl chloride resin. The diaphragm consisted of a polyethylene resin sintered plate and a cationexchange resin membrane. They were placed in contact with each other. The cathodic feeder electrode was a copper plate. The anode was a row of carbon rods. The liquid distributor was a sintered plate of polyethylene resin. The dimensions of fluidized beds are given in Table 1.

The solution, kept at $298 \mathrm{~K}$ in the storage tank, was introduced into the fluidized bed through the distributor and was recycled to the storage tank. Prior to the start of an electrolysis, nitrogen was blown into the storage tank to remove any oxygen.

\subsection{Electrode materials}

The fluidized particles were spherical copper with mean diameters of $3.8 \times 10^{-4}, 5.0 \times 10^{-4}$ and $6.7 \times$ $10^{-4} \mathrm{~m}$. Nitrogen was used as the fluidizing gas. The electrolyte was an aqueous solution of $0.03 \mathrm{kmol}$. $\mathrm{m}^{-3} \mathrm{CuSO}_{4}$ and $1.0 \mathrm{kmol} \cdot \mathrm{m}^{-3} \mathrm{H}_{2} \mathrm{SO}_{4}$. The concentration of copper ion was determined by a chelate titration with EDTA. The electroconductivity of the 
electrolyte was measured by a Kohlrausch bridge circuit.

\section{3 Measurement of holdup}

Gas, liquid and solid holdup in the gas-liquid-solid fluidized beds were measured by using Cell (1) shown in Table 1. Solid holdup, $\varepsilon_{s}$, was determined from the bed expansion. Liquid holdup, $\varepsilon_{l}$, and gas holdup, $\varepsilon_{g}$, were measured by shutting off the flow of gas and liquid simultaneously. In this experiment the level of the fluidized bed nearly coincided with the outlet of the reactor. Each holdup is calculated from the following equations.

$$
\begin{aligned}
& \varepsilon_{s}=H_{0} \varepsilon_{s 0} / H_{f} \\
& \varepsilon_{g}=\left(H_{f}-H_{l}\right) / H_{f} \\
& \varepsilon_{l}=1-\varepsilon_{\mathrm{s}}-\varepsilon_{g}
\end{aligned}
$$

where $H_{0}$ is the settled bed height, $H_{f}$ is the fluidized bed height, $H_{l}$ is the height of quiescent liquid surface and $\varepsilon_{s 0}$ is the solid holdup of settled bed.

\section{4 Electrochemical reaction and electrode potentials}

The electroreduction of copper was carried out at constant current by using a D.C. power supply. In an acidic aqueous solution, the reaction proceeds as follows.

$$
\begin{array}{cl}
\mathrm{Cu}^{2+}+2 \mathrm{e} \rightarrow \mathrm{Cu} & \text { at the cathode } \\
\mathrm{H}_{2} \mathrm{O} \rightarrow 2 \mathrm{H}^{+}+(1 / 2) \mathrm{O}_{2}+2 \mathrm{e} & \text { at the anode }
\end{array}
$$

Two probes were used to determine the potential profiles. The potential in the solution phase, $\Phi_{l}$, was measured with a Luggin capillary probe connected to a saturated silver/silver chloride electrode. The internal diameter of the Luggin capillary was small enough to prevent particles from plugging the salt bridge. The potential in the particle phase, $\Phi_{m}$, was measured with a copper wire. Except for the sensing portion $\left(5 \times 10^{-4} \mathrm{~m}\right.$ diameter and $5 \times 10^{-3} \mathrm{~m}$ long), the wire was sealed in glass tube and insulated with epoxy resin. A set of probes, located at the center of the cathode plate, were moved through the bed laterally in the direction of the current. The potential difference, $\Phi=\Phi_{m}-\Phi_{l}$, was recorded as a function of the lateral position.

\section{5 Effective specific resistance of particle phase}

The charge transfer in the fluidized bed electrode can be expressed in terms of two effective specific resistances; $\rho_{m}$ for the particle phase and $\rho_{l}$ for the solution phase. Under the condition that the concentration of electrolyte is constant in the bed, Ohm's law can be applied to both phases ${ }^{4,8}$. By arranging the equations of Ohm's law, conservation of charge and electrochemical reaction rate with suitable boundary conditions, a set of coupled nonlinear differential equations with respect to $\Phi_{m}$ and $\Phi_{l}$ are obtained as shown in Appendix. By applying the difference approximation to the derivatives, a set of coupled non-

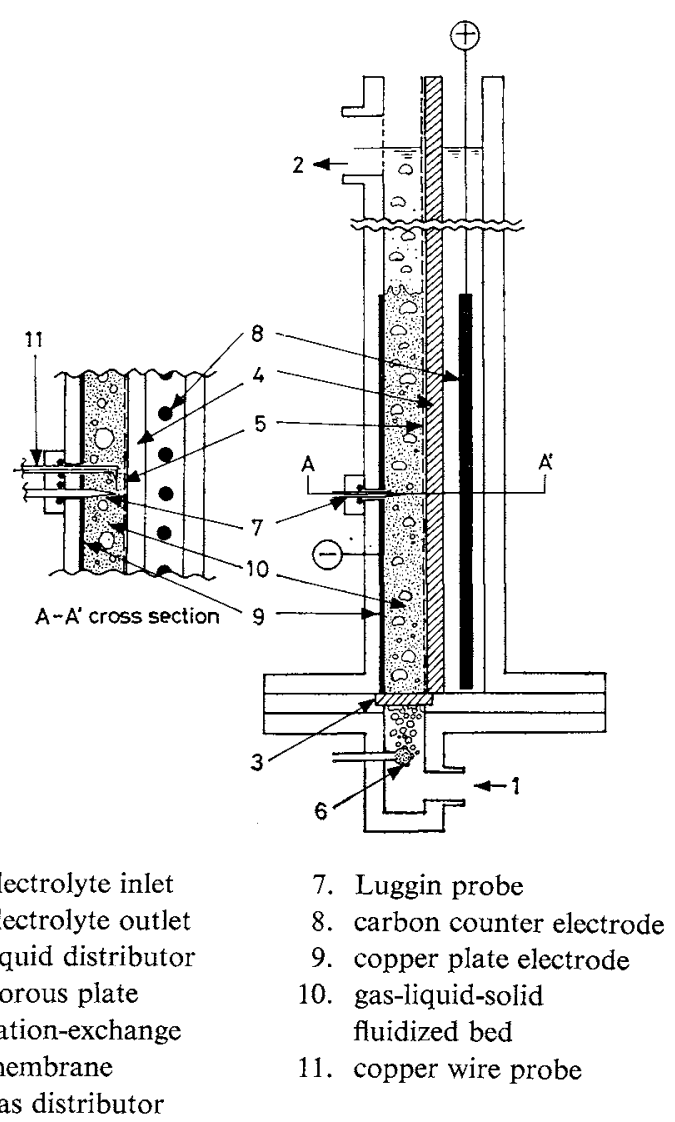

Fig. 1 Schematic diagram of rectangular fluidized bed electrode

Table 1 Dimensions of fluidized bed electrode (Cathode chamber)

\begin{tabular}{lcc} 
& Cell (1) & Cell (2) \\
\hline $\begin{array}{l}\text { Total height (above } \\
\text { distributor) [m] }\end{array}$ & 0.65 & 0.2 \\
Width [m] & 0.15 & 0.04 \\
Thickness [m] & 0.02 & $0.01,0.017$ \\
& $0.009,0.015$ & 0.03 \\
Area of feeder [m $\left.\mathrm{m}^{2}\right]$ & 0.03 & 0.004 \\
Fluidized bed height $[\mathrm{m}]$ & $0.06,0.1,0.2$ & 0.1 \\
\hline
\end{tabular}

linear difference equations are obtained. Next, the theoretical potential profiles are calculated by the successive over-relaxation method with an assumed value of $\rho_{m}$. The correct value of $\rho_{m}$ is determined by comparing the calculated potential difference with the observed one.

The electrochemical parameters necessary in the calculation of $\rho_{m}$ were obtained as follows. Exchange current density and apparent transfer coefficient were measured by using a cylindrical packed bed electrode as described in the previous paper ${ }^{14}$. The value of $\rho_{l}$ was calculated from the Bruggeman relationship ${ }^{3}$.

$$
\rho_{l}=\rho_{l}^{0} / \varepsilon_{l}^{1.5}
$$

where $\rho_{l}^{0}$ is the intrinsic specific resistance of electrolyte. The surface area of spherical particles per unit volume 


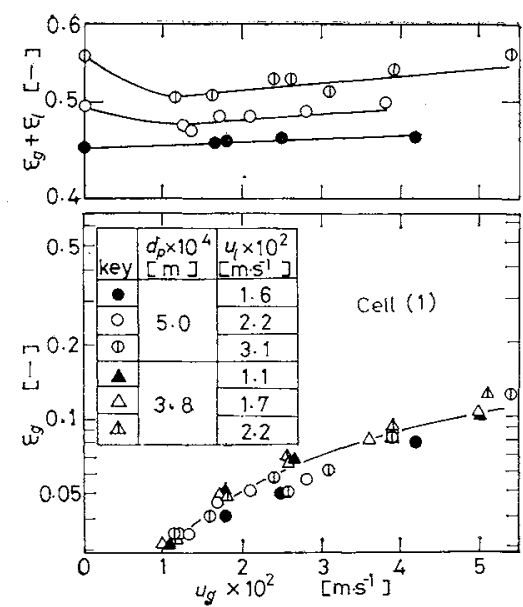

Fig. 2 Effects of gas and liquid velocity on $\left(\varepsilon_{t}+\varepsilon_{g}\right)$ and $\varepsilon_{g}$ in fluidized bed

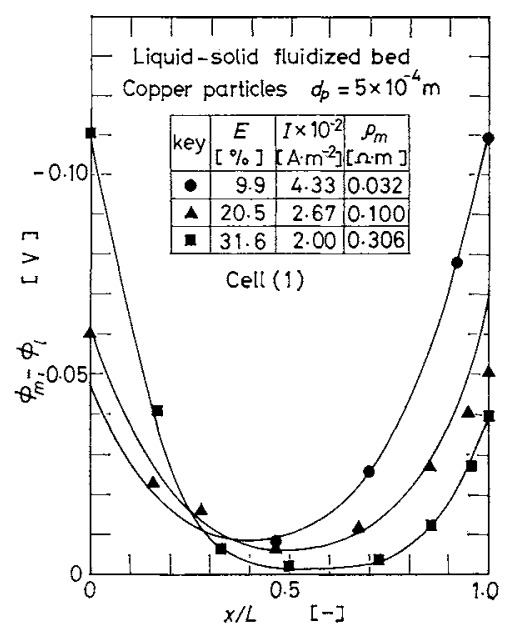

Fig. 3 Potential profiles in liquid-solid fluidized bed

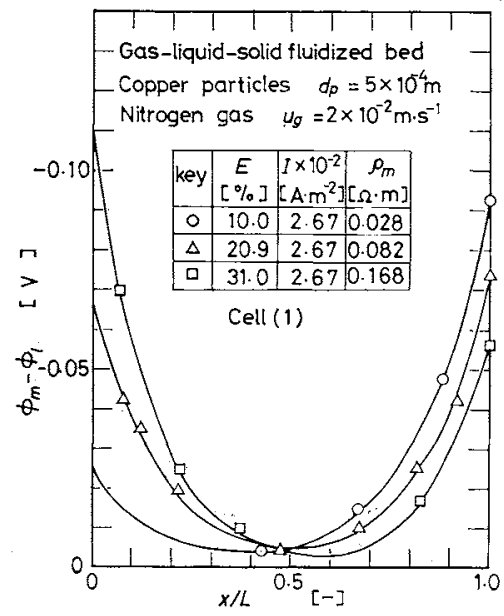

Fig. 4 Potential profiles in gas-liquid-solid fluidized bed

of fluidized bed is given by

$$
a=6 \varepsilon_{s} / d_{p}
$$

\section{6 Overall effective specific resistance}

The overall effective specific resistance of fluidized bed, $\rho_{b}$, was measured by the A.C. electrical circuit proposed by Sabacky et al..$^{17)}$. The fluidized bed electrode was connected in series with a known resistor $R_{k}$. The voltage drops across the fluidized bed and the resistor were measured with a digital voltmeter. The phase angle, $\theta$, was measured with an oscilloscope. By assuming that any capacitance associated with electric double layer is in parallel with the bed resistance, $R_{b}$, the value of $R_{b}$ can be calculated from

$$
R_{b}=\left(R_{k} V_{b}\right) /\left(V_{k} \cos \theta\right)
$$

where $V_{b}$ is the potential drop across the bed, and $V_{k}$ is the potential drop across the known resistor. Because of the rectangular geometry of the bed, the overall effective specific resistance can be calculated from the following equation.

$$
\rho_{b}=R_{b}\left(A / L^{\prime}\right)
$$

where $A$ is the surface area of the flat electrode and $L^{\prime}$ is the distance between the two flat electrodes.

\section{Experimental Results and Discussion}

\section{1 Holdup in gas-liquid-solid fluidized bed}

Figure 2 shows the effects of the superficial liquid and gas velocities on the holdups $\left(\varepsilon_{l}+\varepsilon_{g}\right)$ and $\varepsilon_{g}$ for air-water-copper particles systems. The value of $\left(\varepsilon_{l}+\varepsilon_{g}\right)$ decreased in the range of lower gas velocities, and then increased slightly with increasing gas velocity. The gas holdup was independent of particle diameter and liquid velocity but increased with increase in gas velocity. These tendencies are the same as those reported in the literature ${ }^{11,18,16)}$. The value of $\left(\varepsilon_{l}+\varepsilon_{g}\right)$ for nitrogen-electrolyte-copper particles systems agreed well with that for air-water-copper particles systems.

2. 2 Potential profiles in liquid-solid and gas-liquidsolid fluidized bed electrodes

Figures 3 and 4 show the typical potential distributions in the liquid-solid and gas-liquid-solid fluidized bed electrodes, respectively. The bed expansion, $E$, is defined as $\left\{\left(H_{f} / H_{0}\right)-1\right\} \times 100$. The copper reduction rate increases exponentially with increasing potential difference. The most active regions of the bed are near the feeder at $E=30 \%$, and near the diaphragm at $E=10 \%$. The solid lines in Figs. 3 and 4 show the calculated values from Eqs. (A-11)-(A-13). The experimental data of local electrode potential are well expressed by the present mathematical model.

\section{3 Effective specific resistance of particle phase}

Figure 5 shows that $\rho_{m}$ for liquid-solid systems is independent of the distance between the feeder and diaphargm, $L$. The relationships between the current density based on the total surface area of particles, $I_{t}^{*} /\left(a V_{b e d}\right)$, and the bed expansion are plotted in Fig. 6, 


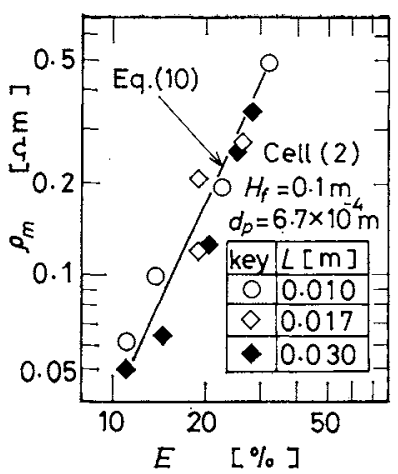

Fig. 5 Effect of bed thickness on $\rho_{m}$ in liquid-solid fluidized bed electrode

where $I_{t}^{*}$ is the total current at $\Phi^{0}=0.1 \mathrm{~V}$. The results indicate that the thinner bed is more active. However, good fluidization will not be maintained in a very thin fluidized bed.

Figure 7 shows the relationship between $\rho_{m}$ and $E$ in the liquid-solid and gas-liquid-solid fluidized beds. For liquid-solid systems, the following experimental equation was reported in the previous paper $^{14)}$, where Cell (2) was used.

$$
\rho_{m}=\left(4 \times 10^{-4} \pm 2 \times 10^{-4}\right) E^{2.0}
$$

The values of $\rho_{m}$ obtained in Cell (1) are $25 \%$ lower than those in Cell (2), but they are within the error of Eq. (10). No effect of $H_{f}$ on $\rho_{m}$ was observed in both beds.

The data of $\rho_{m}$ available at present are also shown in Fig. 7. The data of Fleischmann et al. ${ }^{6}$ ) were corrected by using the exchange current density obtained in this study. The results of Goodridge et al. ${ }^{81}$ and Germain and Goodridge ${ }^{7}$ are much smaller than those of other investigators. Except for the results of Goodridge et al. ${ }^{8}$ and Germain and Goodridge ${ }^{7}$, the values of $\rho_{m}$ agree well with each other. For gasliquid-solid systems, $\rho_{m}$ is independent of $H_{f}$ and $d_{p}$ and increases with increasing bed expansion.

Figure 8 shows the effect of $u_{g}$ on $\rho_{m}$ and $\rho_{l}$. The value of $\rho_{m}$ at $E=10 \%$ is not affected by gas velocity, but in the region of $E>15 \%$ it decreases with increase in gas velocity. Meanwhile, $\rho_{l}$ increases a little with increasing $u_{g}$. As a whole, the gas flow increased the total cell current by $10-30 \%$ at a given cell voltage in the range of $E=15-30 \%$.

\section{4 Mechanism for charge transfer in fluidized bed electrode}

Figure 9 (a) shows the relationship between overall effective specific resistance and bed expansion for liquid-solid systems. The value of $\rho_{b}$ was independent of the frequency of alternating current in the region of $10^{2}$ to $10^{3} \mathrm{~Hz}$. When $\rho_{b}$ is much smaller than $\rho_{l}$, $\rho_{b}$ is equal to the A.C. effective specific resistance of particle phase, $\rho_{m}^{*}$, which is shown by the solid lines

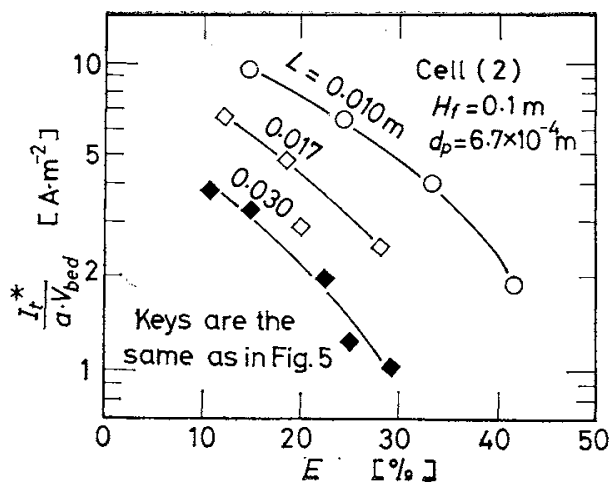

Fig. 6 Relationships between $I_{t}^{*} / a V_{b e d}$ and bed thickness

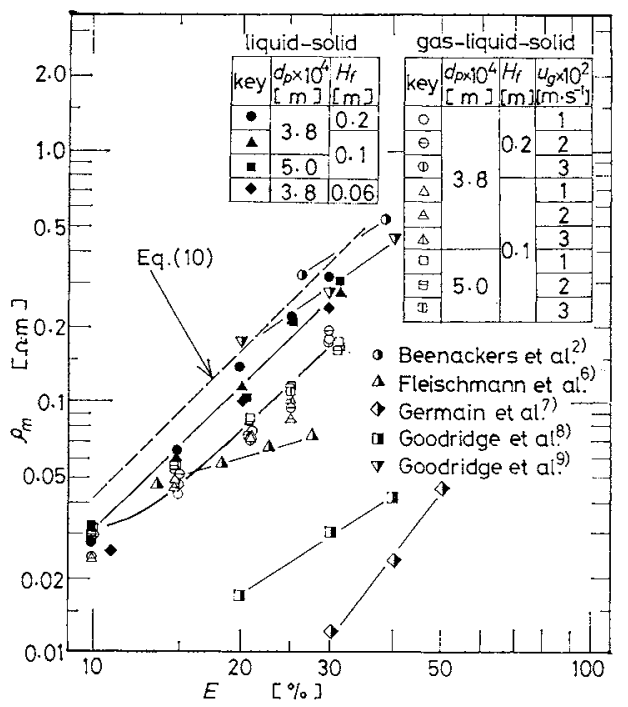

Fig. 7 Specific resistance of particle phase in liquid-solid and gas-liquid-solid fluidized bed electrode

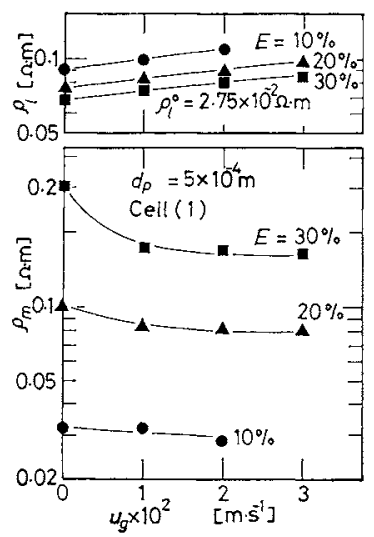

Fig. 8 Effect of gas velocity on $\rho_{m}$ in fluidized bed electrode

in Fig. 9 (a).

As shown in Fig. 10 (a), different mechanisms for charge transfer in the particle phase have been proposed in the literature, and they are explained as follows. 


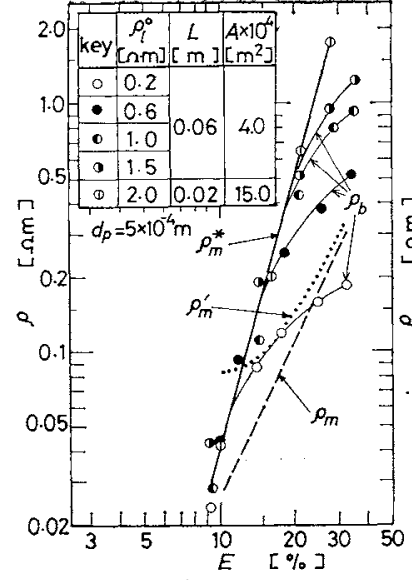

(a)

(a) Liquid-solid systems

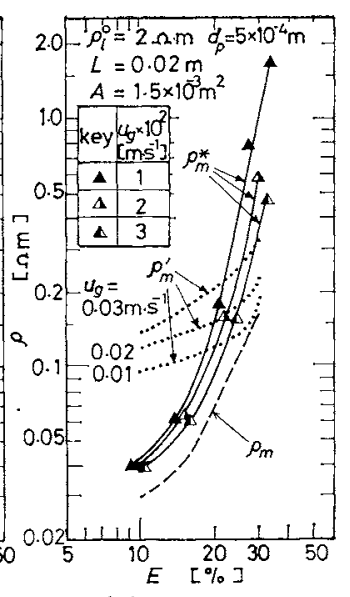

(b) (b) Gas-liquid-solid systems

Fig. 9 Relationships between overall effective specific resistance and bed expansion
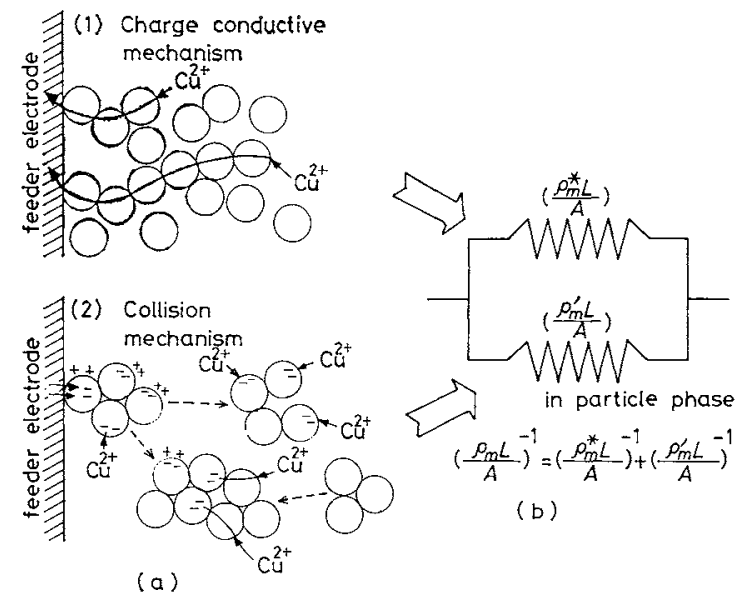

(b)

Fig. 10 Mechanisms for charge transfer in particle phase and parallel effective resistance model

1) Charge conductive mechanism .... Electron conduction proceeds from the feeder to the head of chained or aggregate particles, and there electrochemical reaction occurs ${ }^{17}$.

2) Collision mechanism ... The electrical double layer of aggregates becomes charged by contact with the feeder or aggregates of different charge, and is then discharged either by charge sharing with other aggregates or by electrochemical reaction at different parts of the bed ${ }^{2,5)}$.

However, the effective specific resistance in the particle phase, $\rho_{m}$, must be explained by both mechanisms. Figure 10 (b) shows the parallel effective resistance model which consists of $\rho_{m}^{*}$ and $\rho_{m}^{\prime}$ based on the charge conductive mechanism and the collision mechanism, respectively. $\rho_{m}$ is given by the following equation.

$$
\rho_{m}^{-1}=\left(\rho_{m}^{*}\right)^{-1}+\left(\rho_{m}^{\prime}\right)^{-1}
$$

The value of $\rho_{m}^{\prime}$ calculated from Eq. (11) using the observed values of $\rho_{m}$ and $\rho_{m}^{*}$ is shown by the dotted lines in Fig. 9 (a). The charge transfer in the particle phase seems to be dominated by the charge conductive mechanism at lower bed expansions and by the collision mechanism at higher bed expansions. The value of $\rho_{m}^{\prime}$ obtained by Beenackers et al. ${ }^{2)}$ is about $0.3 \Omega \cdot \mathrm{m}$ at $E=30 \%$ for copper spheres of $5 \times 10^{-4} \mathrm{~m}$ diameter, and is in agreement with the present data in Fig. 9 (a). Tendencies of $\rho_{m}^{*}$ and $\rho_{m}^{\prime}$ for gas-liquid-solid systems are closely similar to those for liquid-solid systems, as shown in Fig. 9 (b). However, the effect of $u_{g}$ on $\rho_{m}^{*}$ and $\rho_{m}^{\prime}$ is the subject for a future study.

\section{Conclusion}

The effective specific resistance of particle phase, $\rho_{m}$, was measured by means of the electroreduction of copper in the liquid-solid and gas-liquid-solid fluidized bed electrodes.

The value of $\rho_{m}$ was not affected by fluidized bed height and particle diameter, but it decreased with increase in gas velocity. In the range of $E=15-30 \%$, the gas flow caused an increase in the total cell current by $10-30 \%$.

The charge transfer rate in the particle phase was analyzed by the parallel effective resistance model, as shown in Fig. 10 (a) and Fig. 10 (b).

\section{Appendix: Calculation of potential profile through the bed}

Figure A-1 shows the one-dimensional three phase model of fluidized bed electrode.

Under the present experimental condition, the concentration of electrolyte was constant due to the low conversion and the turbulence in the bed. The limiting current density calculated from the mass transfer coefficient between particles and the solution proposed by Shirai ${ }^{19\rangle}$ was ten times as large as the current density for the maximum potential difference of $0.1 \mathrm{~V}$ near the feeder and the diaphragm. Therefore, effects of concentration distribution and mass transfer resistance on current density can be neglected. Fundamental equations are as follows.

Ohm's law: $\quad \begin{aligned} & i_{l}=-\left(\rho_{l}^{-1}\right)\left(d \Phi_{l} / d x\right) \\ & i_{m}=-\left(\rho_{m}^{-1}\right)\left(d \Phi_{m} / d x\right)\end{aligned}$

Conservation of charge:

$$
d i_{l} / d x+d i_{m} / d x=0
$$

Electrochemical reaction rate:

$$
\begin{aligned}
d i_{m} / d x= & i_{0} a\left\{\exp \left(\alpha_{a} n F / R T\right)\left(\Phi_{m}-\Phi_{t}\right)\right. \\
& \left.-\exp \left(\alpha_{c} n F / R T\right)\left(\Phi_{m}-\Phi_{l}\right)\right\}
\end{aligned}
$$

and $i_{m}+i_{l}=I$. The boundary conditions are

$$
\begin{array}{ll}
\text { at } x=0 & \text { (cathode) } i_{l}=0, i_{m}=I, \Phi_{l}{ }^{0}=0 \\
\text { at } x=L & \text { (membrane) } \quad i_{l}=I, i_{m}=0
\end{array}
$$

By integrating the sum of Eq. (A-1) and Eq. (A-2) with boundary conditions, one obtains

$$
\Phi_{m}-\Phi_{l}=\left(1+\rho_{l} / \rho_{m}\right) \Phi_{m}-\left(\rho_{l} / \rho_{m}\right) \Phi_{m}{ }^{0}+I \rho_{l} x
$$

The central differences of derivatives with a mesh distance, $h$, are given as follows.

$$
d^{2} \Phi_{m} / d x^{2}=\left(h^{-2}\right)\left\{\Phi_{m}\left(x_{i+1}\right)-2 \Phi_{m}\left(x_{i}\right)+\Phi_{m}\left(x_{i-1}\right)\right\}
$$




$$
d \Phi_{m} / d x=(2 h)^{-1}\left\{\Phi_{m}\left(x_{i+1}\right)-\Phi_{m}\left(x_{i-1}\right)\right\}
$$

By differentiating Eq. (A-2) and substituting Eq. (A-7) into Eq. (A-4), Eq. (A-8) is expressed as follows.

$$
\begin{aligned}
& \left(h^{-2}\right)\left\{\Phi_{m}\left(x_{i+1}\right)-2 \Phi_{m}\left(x_{i}\right)+\Phi_{m}\left(x_{i-1}\right)\right\} \\
& =-\left(\rho_{m} i_{0} a\right)\left[\operatorname { e x p } ( \alpha _ { a } n F / R T ) \left\{\left(1+\rho_{l} / \rho_{m}\right) \Phi_{m}\left(x_{i}\right)\right.\right. \\
& \left.\quad-\left(\rho_{l} / \rho_{m}\right) \Phi_{m}\left(x_{0}\right)+I \rho_{l} x_{i}\right\}-\exp \left(\alpha_{c} n F / R T\right)\left\{\left(1+\rho_{l} / \rho_{m}\right)\right. \\
& \left.\left.\quad \times \Phi_{m}\left(x_{i}\right)-\left(\rho_{l} / \rho_{m}\right) \Phi_{m}\left(x_{0}\right)+I \rho_{l} x_{i}\right\}\right] \equiv \mathrm{f}\left\{x_{i}, \Phi_{m}\left(x_{i}\right)\right\}
\end{aligned}
$$

Finally, the potential profiles are obtained by the successive over-relaxation method.

$$
\begin{aligned}
\Phi_{m}\left(x_{0}\right)^{(k)} & =(1-\omega) \Phi_{m}\left(x_{0}\right)^{(k-1)}+\omega\left[\Phi_{m}\left(x_{1}\right)^{(k-1)}+h \rho_{m} I\right. \\
& \left.-\left(h^{-2} / 2\right) \mathrm{f}\left\{x_{0}, \Phi_{m}\left(x_{0}\right)^{(k-1)}\right\}\right] \\
\Phi_{m}\left(x_{i}\right)^{(k)}= & (1-\omega) \Phi_{m}\left(x_{i}\right)^{(k-1)}+(\omega / 2)\left[\Phi_{m}\left(x_{i+1}\right)^{(k-1)}\right. \\
& \left.+\Phi_{m}\left(x_{i-1}\right)^{(k-1)}-h^{2} \mathrm{f}\left\{x_{i}, \Phi_{m}\left(x_{i}\right)^{(k-1)}\right\}\right] \\
\Phi_{m}\left(x_{n}\right)^{(k)}= & (1-\omega) \Phi_{m}\left(x_{n}\right)^{(k-1)}+\omega\left[\Phi_{m}\left(x_{n}\right)^{(k-1)}\right. \\
& \left.-\left(h^{-2} / 2\right) \mathfrak{f}\left\{x_{n}, \Phi_{m}\left(x_{n}\right)^{(k-1)}\right\}\right]
\end{aligned}
$$

where $\omega$ is the relaxation parameter and $k$ is the iteration number.

\section{Acknowledgment}

The authors would like to acknowledge the assistance of Mr. T. Hasuo, who contributed to this experiment.

\section{Nomenclature}$$
a
$$

$H$

$=$ fluidized bed height

$=$ height of settled liquid surface

$H_{0} \quad=$ settled bed height

$h \quad=$ mesh distance of difference equation

$I \quad=$ total current density

$I_{t}^{*} \quad=$ total current at $\Phi^{0}=0.1 \mathrm{~V}$

$i_{0} \quad=$ exchange current density

$i_{m} \quad=$ current density in particle phase

$i_{l} \quad=$ current density in solution phase

$k=$ iteration number

$L \quad=$ thickness of fluidized bed (distance between flat cathode and membrane)

$L^{\prime} \quad=$ distance between two flat electrodes

$n \quad=$ number of electrons per ion reacted at electrode

$=$ gas constant

$$
\left[\mathrm{J} \cdot \mathrm{K}^{-1} \cdot \mathrm{mol}^{-1}\right]
$$

$=$ bed resistance

= known resistance

$=$ absolute temperature

$=$ superficial gas velocity

$=$ superficial liquid velocity

$=$ potential drop across bed

$=$ fluidized bed volume

$=$ potential drop across known resistor

$=$ distance from flat cathode

$\left[\mathrm{C} \cdot \mathrm{mol}^{-1}\right]$

$[\mathrm{m}]$

[m]

[m]

$\left[\mathrm{A} \cdot \mathrm{m}^{-2}\right]$

$\left[\mathrm{A} \cdot \mathrm{m}^{-2}\right]$

$\left[\mathrm{A} \cdot \mathrm{m}^{-2}\right]$

$\left[\mathrm{A} \cdot \mathrm{m}^{-2}\right.$ ]

$[-]$

$[\mathrm{m}]$

[m]

$\left.\mathrm{ol}^{-1}\right]$

$[\Omega]$

$[\Omega]$

$[\mathrm{K}]$

$\left[\mathrm{m} \cdot \mathrm{s}^{-1}\right]$

$\left[\mathrm{m} \cdot \mathrm{s}^{-1}\right]$

[V]

$\left[\mathrm{m}^{3}\right]$

[V]

[m]

$=$ apparent transfer coefficient for anodic reaction

$=$ apparent transfer coefficient for cathodic reaction

$\begin{array}{ll}\varepsilon_{g} & =\text { gas holdup } \\ \varepsilon_{l} & =\text { liquid holdup }\end{array}$

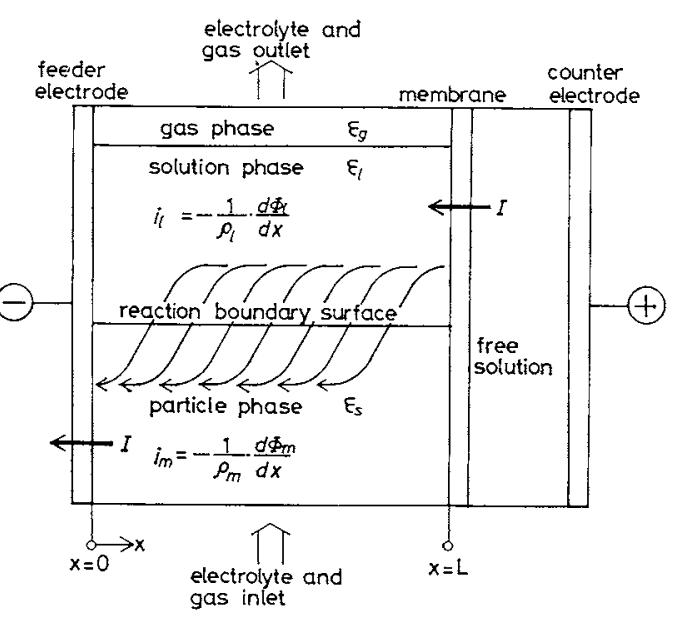

Fig. A-1 One-dimensional three phase model of fluidized bed electrode $\varepsilon_{s}$

$\varepsilon_{s 0}$

$\theta$

$\rho_{b}$

$\rho_{m}$

$\rho_{m}^{*}$

$\rho_{m}^{\prime}$

$\rho_{l}$

$\rho_{l}^{0}$

$\Phi$

$\phi^{0}$

$\emptyset_{m}$

$\Phi_{m}{ }^{0}$

$\Phi_{l}$

$\Phi_{l}{ }^{0}$

$\omega$
$=$ solid holdup

$=$ solid holdup in settled bed

$=$ phase angle

$=$ overall effective specific resistance in bed

$=$ effective specific resistance of particle phase

$=$ A.C. effective specific resistance based on charge conductive mechanism

$=$ effective specific resistance based on collision mechanism

$=$ effective specific resistance of solution phase

$=$ intrinsic specific resistance of electrolyte

$=$ potential difference $\left(=\Phi_{m}-\Phi_{l}\right)$

$=\Phi$ at $x=0$

$=$ potential of particle phase

$=$ potential of particle phase at $x=0$

$=$ potential of solution phase

$=$ potential of solution phase at $x=0$

$=$ relaxation parameter
$[-]$

$[-]$

$[\mathrm{rad}]$

$[\Omega \cdot \mathrm{m}]$

$[\Omega \cdot \mathrm{m}]$

$[\Omega \cdot \mathrm{m}]$

$[\Omega \cdot \mathrm{m}]$

$[\Omega \cdot \mathrm{m}]$

$[\Omega \cdot \mathrm{m}]$

[V]

$[\mathrm{V}]$

$[\mathrm{V}]$

[V]

[V]

$[\mathrm{V}]$

[-]

\section{Literature Cited}

1) Bareau, J. Y. and F. Coeuret: J. Appl. Electrochem., 9, 737 (1979).

2) Beenackers, A. A. C. M., W. P. M. van Swaaij and A. Welmers: Electrochim. Acta, 22, 1277 (1977).

3) De La Rue, R. E. and C. W. Tobias: J. Electrochem. Soc., 106, 827 (1959).

4) Fleischmann, M. and J. W. Oldfield: J. Electroanal. Chem., 29, 211 (1971).

5) idem: ibid., 29, 231 (1971).

6) Fleischmann, M., J. W. Oldfield and L. Tennakoon: $J$. Appl. Electrochem., 1, 103 (1971).

7) Germain, S. and F. Goodridge: Electrochim. Acta, 21, 545 (1976).

8) Goodridge, F., D. I. Holden, H. D. Murray and R. E. Plimley: Trans. Inst. Chem. Eng., 49, 128 (1971).

9) idem: ibid., 49, 137 (1971).

[-] 10) Hutin, D. and F. Coeuret: J. Appl. Electrochem., 7, 463 (1977).

[-] 11) Kim, S. D., C. G. J. Baker and M.A. Bergougnou: Can. J.

[-] Chem. Eng., 53, $134(1975)$.
[-] 12) Kreysa, G.: Electrochim. Acta, 23, 1351 (1978). 
13) Morooka, S., K. Kusakabe and Y. Kato: Kagaku Kogaku Ronbunshu, 5, 162 (1979).

14) Morooka, S., K. Kụsakabe, T. Watari and Y, Kato: ibid., 6, 40 (1980).

15) Oloman, C. and A. P. Watkinson: Can. J. Chem. Eng., 53, 268 (1975).

16) Østergaard, K. and P. I. Thisen: Chem. Eng. Sci., 21, 413
(1966).

17) Sabacky, B. J. and J. W. Evans: Metall. Trans., 8B, 5 (1977).

18) Sabacky, B. J. and J. W. Evans: J. Electrochem. Soc., 126, 1180 (1979).

19) Shirai, T.: "Ryudoso", p. 207, Kagaku Gijutsusha, Kanazawa (1964)

\title{
COMPARISON AMONG MEASURING METHODS OF DENSITY OF SPHERICAL AEROSOL PARTICLES
}

\author{
YASUO KOUSAKA, KIKUO OKUYAMA, \\ YoSHIYUKI ENDO AND HIROSHI TANAKA \\ Department of Chemical Engineering, University of Osaka \\ Prefecture, Sakai, Osaka, 591
}

\begin{abstract}
Three basically different principles for density measurement of aerosol particles, based on 1) separate measurements of mass concentration and size distribution, 2) simultaneous measurements of gravitational settling velocity and electrical mobility and 3) balance of gravitational and Coulomb's force, have been tested. Modifications by combining classification of particles by electric differential mobility analyser to each of the above three methods have also been tested. The easiest and most accurate method has been found to be that based on 3) above, which is similar to Millikan's experiment for the evaluation of elementary charge, when particles are larger than $0.5 \mu \mathrm{m}$. For smaller particles the method based on 1) above is applicable, but there is a problem in accuracy and there is a disadvantage in that the method requires stability in aerosol concentration and size during density measurement.
\end{abstract}

\section{Introduction}

In conversion of an aerodynamic diameter to the Stokes diameter of an aerosol particle, the density of the particle should be known. Frequently, however, the density of an aerosol particle is unknown. Even if the true density of material is known, the density of some aerosol particles is quite different from the true density because of porous structure. This is one of the reasons why the aerodynamic diameter has often been used in discussing dynamic behavior of aerosol particles. When the dynamic behavior of an aerosol particle is discussed in connection with collision radius, mobility, diffusion coefficient and Cunningham correction factor, the aerodynamic diameter is not enough to evaluate the behavior. Since the particle diameter observed by a light-scattering method or an electron microscope cannot give us any information on density, dynamic behavior of such a particle cannot be precisely discussed.

\footnotetext{
Received June 14, 1980. Correspondence concerning this article should be addressed to $Y$. Kousaka.
}

Fuchs describes in his book ${ }^{2}$ several methods to determine the density of an aerosol particle. Since then, various methods or instruments have been developed and improved to measure accurately the properties of aerosol particles. Using the recent advanced instrumentation of aerosol measurement, accurate and simple techniques for measuring particle density may be developed.

In this study, several advanced methods of measuring the density of aerosol particles were tested and the results obtained were compared using DOP particles of known density as the standard particles to determine the advantageous methods among them. Then the densities of several aerosol particles were measured and experimental results were compared with true densities of the material of aerosol particles.

\section{Principles of the Methods Tested}

1. 1 Method based on measurement of mass concentration and size distribution of aerosol particles (hereafter Method I)

Method I in Fig. 1 shows the principle and procedure 